\section{Correspondence on 'MRI lesions in the sacroiliac joints of patients with spondyloarthritis: an update of definitions and validation by the ASAS MRI working group'}

The use of MRI in the evaluation of axial spondyloarthritis (axSpA) has become more established particularly over the past decade. The Assessment in SpondyloArthritis International Society (ASAS) has previously developed criteria for axSpA that incorporated clinical and imaging aspects including the use of MRI in the detection of active sacroiliitis. ${ }^{12}$ In addition to active inflammation represented by bone marrow oedema (BMO), MRI can demonstrate several structural changes that reflect chronic inflammation accumulated during the natural history of axSpA. Although the presence of structural sacroiliac joint (SIJ) changes on their own is not sufficient to meet the ASAS definition for a positive MRI, these features can influence the diagnosis when it is unclear whether the BMO lesion(s) meet the ASAS criterion. ${ }^{2}$

We read with great interest the article by Maksymowych et al, which provided an update on the ASAS standardised definitions of SIJ MRI lesions in axSpA and these lesions were also evaluated in a validation exercise performed by the ASAS MRI working group, demonstrating an overall acceptable reliability in the MRI lesions assessment. ${ }^{3}$ We conducted a study that aimed to test the interobserver reliability in the detection of individual SIJ lesions on MRI among clinically proven cases of ax-SpA evaluated by musculoskeletal radiologists to test the generalisability. Following approval from the institutional research ethics board with a waiver for informed consent, the departmental radiology database of a tertiary care academic hospital was used to search for subjects who underwent dedicated SIJ MRI for the assessment of axSpA. Ninety-four consecutive cases of axSpA (188 SIJs) were included in the study. Each SIJ MRI scan was scored for BMO as a sign of active inflammation, and for fat lesions, erosions, sclerosis and ankylosis as features of chronic structural change. BMO, erosions and fat lesions were scored on each SIJ quadrant (upper iliac, lower iliac, upper sacral, lower sacral), while sclerosis and SIJ ankylosis was recorded as present or absent at each SIJ. MRI scoring was performed by two musculoskeletal radiologists with 7 and 11 years of experience in reading dedicated axSpA MRI. The scores of the two readers were compared using kappa statistics. ${ }^{4}$

BMO was scored in 98/188 (52\%) and 69/188 (37\%) of the SIJs, and the number of SIJs which had structural changes without BME was 86/188 (46\%) and 63/188 (34\%), according to readers 1 and 2, respectively. Mean (95\% CI) kappa value for BMO scoring was $0.48(0.38-0.58)$, for erosions $0.27(0.18-$ $0.35)$ and for fat lesions $0.65(0.58-0.73)$. Kappa value for the assessment of sclerosis was $0.6(0.09-1.11)$ and for ankylosis 0.87 (0.84-0.9). More details of the MRI scoring are provided in table 1 . The results indicate moderate agreement for the assessment of active inflammation at the SIJ represented by BMO. Assessment of structural changes on MRI showed almost perfect agreement in the evaluation of ankylosis, moderate agreement for sclerosis, substantial agreement for fat lesions and fair agreement for erosions assessment.

Overall, and except for erosions, the results of this work are comparable and support the finding of the prior studies including the ASAS validation exercise,${ }^{3}$ demonstrating adequate MRI reliability in the evaluation of both active inflammatory and structural changes at the SIJ. ${ }^{3}{ }^{5}$ Erosions can often be a challenging and complex feature to call on MRI with high confidence. The ASAS criteria for a positive MRI remain primarily based on the detection of BMO at the SIJ that must be highly suggestive of $\mathrm{SpA}$ and other features are considered supportive but not required to meet the definition at the present time. ${ }^{2} \mathrm{We}$ believe that this study confirms that MRI continues to be a reliable imaging modality in providing global SIJ assessment in the context of suspected axSpA in standard practice.

Zaid Jibri ๑ ,' Ummugulsum Gazel, ${ }^{2}$ Dilek Solmaz $\odot{ }^{3}$ Gizem Ayan $\odot$, ,,4 Jacob Karsh, ${ }^{2}$ Sibel Zehra Aydin, ${ }^{2,4}$ Marcos Sampaio ${ }^{1}$

${ }^{1}$ Department of Medical Imaging, The Ottawa Hospital, Ottawa, Ontario, Canada ${ }^{2}$ Division of Rheumatology, University of Ottawa, Ottawa, Ontario, Canada ${ }^{3}$ Department of Internal Medicine, Division of Rheumatology, Izmir Katip Celebi Universitesi Tip Fakultesi, Izmir, Turkey

${ }^{4}$ Ottawa Hospital Research Institute, Ottawa, Ontario, Canada

Correspondence to Dr Zaid Jibri, Department of Medical Imaging, Ottawa Hospital, Ottawa K1H 8L6, Canada; zaid.jibri@icloud.com

Twitter Zaid Jibri @ JibriZaid

Contributors All authors have made significant contribution to this work.

Table 1 Scoring summary of sacroiliac joint MRI features between the two readers and interobserver agreement

\begin{tabular}{|c|c|c|c|c|c|c|c|c|c|c|c|c|}
\hline \multirow[b]{2}{*}{ Localisation } & \multicolumn{4}{|l|}{ BMO } & \multicolumn{4}{|l|}{ Erosion } & \multicolumn{4}{|l|}{ Fat lesion } \\
\hline & $\begin{array}{l}\mathrm{N} \\
\text { (Reader 1) }\end{array}$ & $\begin{array}{l}\mathrm{N} \\
\text { (Reader 2) }\end{array}$ & Kappa & $\begin{array}{l}\text { Positive } \\
\text { agreement } \\
(\%)\end{array}$ & $\begin{array}{l}\mathrm{N} \\
\text { (Reader 1) }\end{array}$ & $\begin{array}{l}\mathrm{N} \\
\text { (Reader 2) }\end{array}$ & Kappa & $\begin{array}{l}\text { Positive } \\
\text { agreement } \\
(\%)\end{array}$ & $\begin{array}{l}\mathrm{N} \\
\text { (Reader 1) }\end{array}$ & $\begin{array}{l}\mathrm{N} \\
\text { (Reader 2) }\end{array}$ & Kappa & $\begin{array}{l}\text { Positive } \\
\text { agreement (\%) }\end{array}$ \\
\hline R-upper iliac & 30 & 22 & 0.58 & 69 & 74 & 39 & 0.19 & 64 & 21 & 27 & 0.66 & 75 \\
\hline R-lower iliac & 34 & 16 & 0.43 & 56 & 66 & 25 & 0.26 & 55 & 21 & 25 & 0.65 & 74 \\
\hline R-upper sacral & 30 & 20 & 0.55 & 69 & 53 & 17 & 0.17 & 40 & 33 & 36 & 0.74 & 84 \\
\hline R-lower sacral & 16 & 12 & 0.66 & 71 & 28 & 11 & 0.41 & 51 & 27 & 31 & 0.79 & 86 \\
\hline L-upper iliac & 27 & 25 & 0.47 & 62 & 74 & 31 & 0.19 & 57 & 27 & 29 & 0.53 & 68 \\
\hline L-lower iliac & 32 & 23 & 0.31 & 51 & 66 & 26 & 0.20 & 52 & 27 & 30 & 0.56 & 70 \\
\hline L-upper sacral & 37 & 34 & 0.48 & 68 & 53 & 21 & 0.28 & 51 & 42 & 39 & 0.58 & 77 \\
\hline L-lower sacral & 15 & 8 & 0.36 & 43 & 29 & 12 & 0.43 & 54 & 29 & 35 & 0.66 & 78 \\
\hline \multirow{2}{*}{$\begin{array}{l}\text { Mean kappa values } \\
(95 \% \mathrm{Cl})\end{array}$} & \multicolumn{4}{|c|}{$0.48(0.38$ to 0.58$)$} & \multicolumn{4}{|c|}{0.27 (0.18 to 0.35$)$} & \multicolumn{4}{|c|}{0.65 (0.58 to 0.73$)$} \\
\hline & \multicolumn{4}{|l|}{ Sclerosis } & \multicolumn{8}{|l|}{ Ankylosis } \\
\hline R sacroiliac joint & 15 & 25 & 0.56 & 65 & 20 & 18 & 0.86 & 89 & & & & \\
\hline L sacroiliac joint & 14 & 20 & 0.64 & 71 & 21 & 19 & 0.87 & 90 & & & & \\
\hline $\begin{array}{l}\text { Mean Kappa values } \\
(95 \% \mathrm{Cl})\end{array}$ & \multicolumn{4}{|c|}{0.60 (0.09 to 1.11$)$} & \multicolumn{4}{|c|}{0.87 (0.84 to 0.9$)$} & & & & \\
\hline
\end{tabular}


Funding The authors have not declared a specific grant for this research from any funding agency in the public, commercial or not-for-profit sectors.

Competing interests None declared.

Patient and public involvement Patients and/or the public were not involved in the design, or conduct, or reporting, or dissemination plans of this research.

Patient consent for publication Not required.

Provenance and peer review Not commissioned; internally peer reviewed.

(c) Author(s) (or their employer(s)) 2021. No commercial re-use. See rights and permissions. Published by BMJ.

\section{(A) Check for updates}

To cite Jibri Z, Gazel U, Solmaz D, et al. Ann Rheum Dis Epub ahead of print: [please include Day Month Year]. doi:10.1136/annrheumdis-2021-220008

Received 1 February 2021

Accepted 3 February 2021

\section{SLinked}

http://dx.doi.org/10.1136/annrheumdis-2021-220078
Ann Rheum Dis 2021;0:1-2. doi:10.1136/annrheumdis-2021-220008

\section{ORCID iDs}

Zaid Jibri http://orcid.org/0000-0001-6923-6829

Dilek Solmaz http://orcid.org/0000-0002-9035-689X

Gizem Ayan http://orcid.org/0000-0003-1889-9619

\section{REFERENCES}

1 Rudwaleit M, van de Heijde D, Landewe R. Correction: The development of assessment of SpondyloArthritis international society classification criteria for axial spondyloarthritis (part II): validation and final selection. Ann Rheum Dis 2019;78:e59.

2 Lambert RGW, Bakker PAC, van der Heiide D, et al. Defining active sacroiliitis on MRI for classification of axial spondyloarthritis: update by the ASAS MRI Working group. Ann Rheum Dis 2016;75:1958-63.

3 Maksymowych WP, Lambert RG, Østergaard M, et al. Mri lesions in the sacroiliac joints of patients with spondyloarthritis: an update of definitions and validation by the ASAS MRI Working group. Ann Rheum Dis 2019;78:1550-8.

4 Landis JR, Koch GG. The measurement of observer agreement for categorical data. Biometrics 1977:33:159-74.

5 Maksymowych WP, Pedersen SJ, Weber U, et al. Central reader evaluation of MRI scans of the sacroiliac joints from the ASAS classification cohort: discrepancies with local readers and impact on the performance of the ASAS criteria. Ann Rheum Dis 2020;79:935-42. 